\title{
Prevalence of Peri-implant Diseases Associated with a Rough-Surface Dental Implant System: 9 Years after Insertion
}

\author{
${ }^{1}$ Peer W Kämmerer, ${ }^{2}$ Karl M Lehmann, ${ }^{1}$ Julia Karbach, ${ }^{2}$ Joachim Wegener, ${ }^{3}$ Bilal Al-Nawas, ${ }^{4}$ Wilfried Wagner \\ ${ }^{1}$ Resident, Department of Oral and Maxillofacial Surgery, University Medical Center, Mainz, Germany \\ ${ }^{2}$ Resident, Department of Prosthetic Dentistry, University Medical Center, Mainz, Germany \\ ${ }^{3}$ Assistant Medical Director, Department of Oral and Maxillofacial Surgery, University Medical Center, Mainz, Germany \\ ${ }^{4}$ Medical Director, Department of Oral and Maxillofacial Surgery, University Medical Center, Mainz, Germany
}

Correspondence: Peer W Kämmerer, Resident, Department of Oral and Maxillofacial Surgery, University Medical Center, Augustusplatz 2, 55131, Mainz, Germany, Phone: +49-6131 17 7334, Fax: +49-6131 17 6602, e-mail: peer.kaemmerer@unimedizin-mainz.de

\section{ABSTRACT}

Introduction: The aim of this study was a retrospective clinical evaluation of the long-term prevalence of peri-implant diseases associated with a modern rough-surface dental implant system.

Materials and methods: A total of 237 implants were inserted in 47 patients between 1994 and 2005. Peri-implant parameters (sulcus bleeding, pocket depth and bone loss) were evaluated at a mean of 9.1 years after insertion. Based on these parameters, cases were classified as healthy tissue, peri-implant mucositis and peri-implantitis. One-way analysis of variance was used to compare group parameters.

Results: A total of 211 implants (89\%) were healthy, 21 implants (9\%) showed peri-implant mucositis and 5 (2\%) showed peri-implantitis. Risk factors for peri-implant diseases were alcohol $(p<0.001)$ and nicotine abuse $(p<0.001)$ and irradiation $(p<0.001)$.

Conclusion: After a mean of 9.1 years, the TiOblast ${ }^{\circledR}$ dental implant showed a marginal rate of peri-implant disease. The calculated risk factors for development of peri-implant diseases are in accordance to previous studies.

Keywords: Implant, Gingivitis, Mucositis, Peri-implant disease, Bone loss.

\section{INTRODUCTION}

Inflammatory lesions that develop in the tissues around dental implants are collectively known as peri-implant diseases. Etiopathogenesis of early and late peri-implantitis is not well understood. A relation to peri-implant environment, to soft tissue/implant interface, to patientrelated factors (smoking, systemic diseases, plaque control) and to a host-parasite equilibrium is likely. A number of studies have shown that bacterial infection plays the most important role in the failure of dental implants. ${ }^{1-5}$ In particular, adherence and colonization of microorganisms to plaque-exposed biomaterials, such as titanium, are discriminant factors for the development of an infection. ${ }^{6}$ Though, the bacterial biofilm alone is insufficient to explain the disease initiation and progression. ${ }^{7}$ A peri-implant disease following successful integration of an endosseous implant may be the result of a discrepancy between bacterial challenge and host response. Accordingly, it has been suggested that periodontal tissue destruction is mainly attributable to the host's inflammatory response to the bacterial challenge. Other factors, including diabetes mellitus, nicotine and alcohol abuse, gender and irradiation, have been shown to modify the host response to the bacterial challenge and may increase the risk for periodontal disease in time.

Studies of periodontal diseases are complicated by a diversity of methodologies and definitions. ${ }^{8}$ To receive homogenous data regarding prevalence and severity of such biological complications, a consensus regarding definitioncriteria is required. In accordance with the classification of periodontal disease, peri-implant disease includes two entities: Peri-implant mucositis and peri-implantitis. Definitions of the two peri-implant disease entities were proposed in a consensus report from the 1st European Workshop on Periodontology (EWOP). ${ }^{9}$ Peri-implant mucositis was defined as a reversible inflammatory reaction in the soft tissues surrounding a functioning implant, and peri-implantitis was described as inflammatory reactions associated with loss of supporting bone around an implant (Fig. 1). ${ }^{10-12}$

As there have been few long-term studies concerning the prevalence of peri-implant diseases, the aim of this study was to evaluate the long-term prevalence of peri-implant disease associated with a rough-surface dental implant system, together with possible risk factors. 


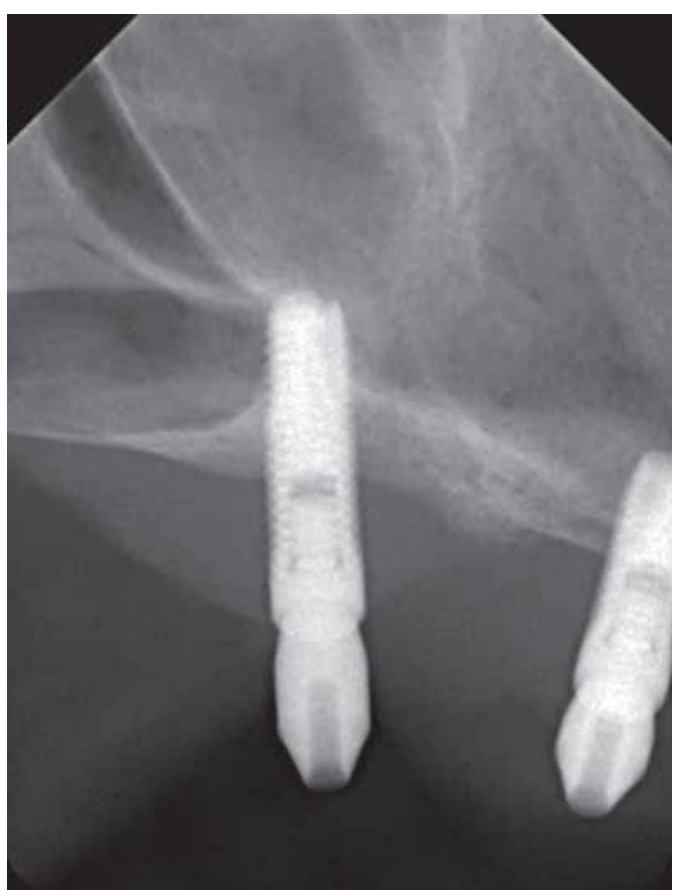

Fig. 1: Peri-implantitis with severe bone loss for an implant inserted in the maxilla

\section{MATERIALS AND METHODS}

\section{Patients and Implants}

From 1994 to 2000, 41 patients (25 men and 16 women; mean age, 57 years) were admitted for treatment with implant-supported prostheses. Eligible subjects were provided with oral rehabilitation by fixed partial dentures and implant-supported overdentures. A total of 237 implants (TiOblast $^{\circledR}$; Astra Tech, Mölndal, Sweden) were applied (116 in men and 121 in women). The implant system was first tested in clinical trials in $1992 .{ }^{13}$ The implants are made from commercially pure titanium which is blasted with particles of titanium dioxide $\left(\mathrm{TiO}_{2}\right)$. They are screw shaped, surface enlarged and equipped with self-tapping anchorage. The connection between the fixture and the abutment is conical, and the surface is moderately rough with a Sa value of $1.10 \mathrm{~mm} \cdot{ }^{14,15}$ A total of 86 implants were placed in the maxilla; and 151 in the mandible. At the time of data collection, the implants were in situ for a mean time of 9.12 years (5.3-11.23). Exclusion criteria were as follows: A history of drug abuse and/or life-threatening diseases, severe maxillomandibular skeletal discrepancy or excessive parafunctional activity leading to wearing of prosthetic teeth or fracture of dentures. Treatment planning for each patient was based on the individual anatomical and morphological situation, the patient's expectations and esthetic and cosmetic considerations.

\section{Surgical and Prosthetic Procedures}

All patients were treated by oral and maxillofacial surgeons and prosthodontists in the same department using the same systematic, submerged surgical protocol. ${ }^{16}$ In cases of insufficient bone volume for reliable implant placement, augmentation and elevation of the maxillary sinus floor were performed. Three months after sinus augmentation, the dental implants were inserted under local anesthesia. The inserted implants differed in diameter (3.5 and $4.0 \mathrm{~mm}$ ) and in effective length (8, 9, 11, 13, 15, 17 and $19 \mathrm{~mm})$. In all cases, prosthetic rehabilitation was facilitated by using surgical templates to correctly align and position the implants. After the healing periods (3 months after augmentation, 6 months after implant placement), the patient's conventional dentures were adjusted when possible and supplied with a soft liner. Two weeks after the second stage of surgery, standard prosthetic treatment was carried out, including the fabrication of implant-retained fixed partial dentures and implant-supported removable partial dentures. Most of the implants (79\%) were provided with bar-retained overdentures, while $12 \%$ of the implants received a crown, $2 \%$ received a bridge, $3 \%$ received an extension bridge and $4 \%$ received no prosthetic treatment.

\section{Clinical Analysis}

The clinical analysis included the sulcus bleeding index (SBI) according to Mühlemann and $\operatorname{Son}^{17}(0=$ normal gingiva, no bleeding with a periodontal probe; $1=$ normal gingiva, bleeding; 2 = inflammatory altered gingiva, bleeding; 3 = inflammatory swelling of the gingiva, bleeding; 4 = profuse inflammatory swelling, bleeding and $5=$ necrosis of the gingiva). Periodontal pocket depth (PPD) was measured to the nearest millimeter with a plastic periodontal probe (\#12 Colorvue; Hu-Friedy, Chicago, IL, USA) at mesial, distal, oral and vestibular sites.

\section{Radiographic Analysis}

Radiography via orthopantomogram was performed at the time of follow-up examination. The current and postoperative orthopantomograms were compared to evaluate the distance from the implant-abutment periphery to the apex of the implant; the data were then pooled to calculate the average marginal bone loss. ${ }^{18}$ With limitations, this method has been shown to be reliable for this purpose. ${ }^{18,19}$ The cases were divided into two groups according to bone loss around adjacent implants: Time-dependent regular bone loss and pathological bone loss. ${ }^{20}$

\section{Classification of Tissue Conditions}

Peri-implant conditions were classified as healthy tissue, mucositis or peri-implantitis. Healthy tissue was defined as $\mathrm{PPD}<5 \mathrm{~mm}$ and/or $\mathrm{SBI} \leq 1$. Non-inflammatory bone loss was not taken into account. Peri-implant mucositis was defined as $\mathrm{SBI}>1$, PPD $>5 \mathrm{~mm}$ and no pathological bone loss ( $\leq 2 \mathrm{~mm}$ in the first year and $0.2 \mathrm{~mm}$ in each subsequent year). Peri-implantitis was diagnosed when SBI $>1$, PPD 


\begin{tabular}{|c|c|c|c|}
\hline Parameter & Healthy tissue conditions & Peri-implant mucositis & Peri-implantitis \\
\hline Sulcus bleeding index & 0-1 & $2-4$ & $2-4$ \\
\hline Periodontal pocket depth & $<5 \mathrm{~mm}$ & $>5 \mathrm{~mm}$ & $>5 \mathrm{~mm}$ \\
\hline Bone loss & & $\leq 2 \mathrm{~mm} 1$ st year and $\leq 0.2 \mathrm{~mm} /$ year & $>2 \mathrm{~mm} 1 \mathrm{st}$ year and $>0.2 \mathrm{~mm} /$ year \\
\hline Number of implants & 211 & 21 & 5 \\
\hline
\end{tabular}

$>5 \mathrm{~mm}$ and pathological bone loss of $>2 \mathrm{~mm}$ in the $1 \mathrm{st}$ year and $>0.2 \mathrm{~mm}$ in each subsequent year was detected (Table 1).

\section{Anamnesis}

Information about the patient's concomitant diseases, smoking status and alcohol consumption was obtained with a structured questionnaire.

\section{Statistical Analysis}

Descriptive statistics were calculated for all clinical and radiographic parameters. One-way analysis of variance (ANOVA) was performed to compare groups. Fisher's exact test was used to determine the influence of different parameters. In all analyses, $\mathrm{p}<0.05$ was taken to indicate statistical significance.

\section{RESULTS}

All patients included in the follow-up completed the questionnaire. With regard to concomitant diseases, seven patients had no systemic disease, one had diabetes mellitus type 2, one had hepatitis A and two patients had osteoporosis. Three patients were smokers, and three had a history of alcohol abuse. Six percent of the patients had known radiation anamnesis and received 78 implants. Sixtyeight percent of the implants were inserted without osseous augmentation, and $27 \%$ received augmentation. The mean SBI around the implants was $0.73 \pm 0.69$ (Fig. 2). The mean PPD for all implants was $2.94 \pm 1.29 \mathrm{~mm}$ (Fig. 3). Marginal bone loss changes within the range of regular bone loss ${ }^{20}$ (Fig. 3) were observed in 232 (98\%) of the implants. The results regarding patients with healthy peri-implant tissue conditions, peri-implant mucositis and peri-implantitis are presented in Table 1. Risk factors for peri-implant diseases (peri-implant mucositis and peri-implantitis vs healthy tissue) were alcohol ( $p<0.001)$, nicotine abuse $(\mathrm{p}<0.001)$ and irradiation $(\mathrm{p}<0.001)$. Incidence of peri-implant mucositis and peri-implantitis in relation to time since implantation is shown in Figure 4. No correlation was seen between time and peri-implant disease.

\section{DISCUSSION}

This retrospective study on the prevalence of peri-implant diseases associated with the TiOblast dental implant was

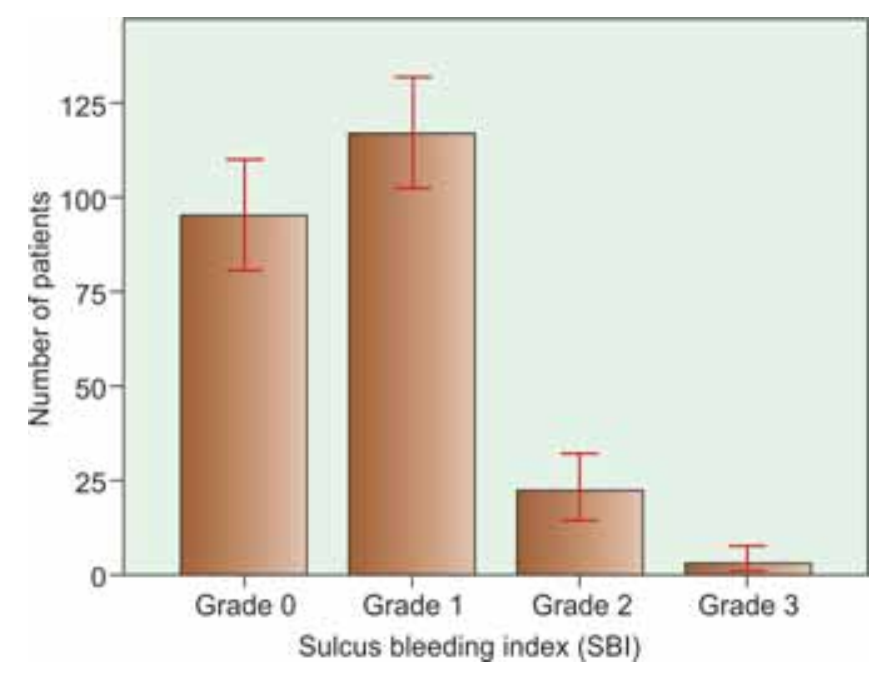

Fig. 2: The majority of implants exhibited a sulcus bleeding index (SBI) of $\leq 1$ (with $95 \%$ confidence intervals)

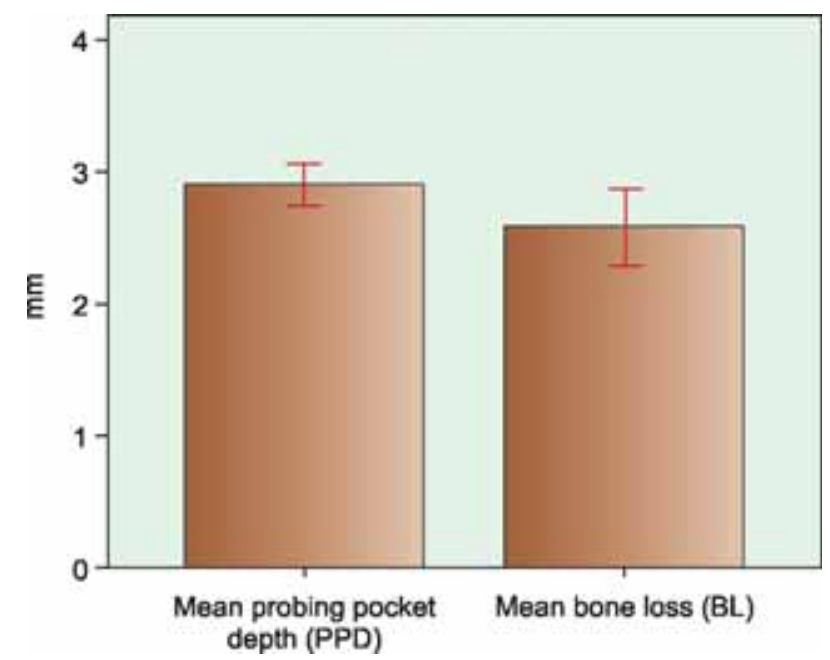

Fig. 3: Mean periodontal pocket depth (PPD) and mean regular bone loss (BL) of implants (with 95\% confidence intervals)

carried out to add to the limited data available in the literature. As it has been reported that the implant design may be important with regard to the incidence of periimplant disease, ${ }^{21}$ it is desirable to eliminate implant design as a confounding variable when analyzing factors associated with the development of biological complications. Accordingly, all patients in this study were treated with the same implant system. Further, the lack of standardized and internationally recognized success criteria makes it difficult to compare different studies. In fact, some authors defined 


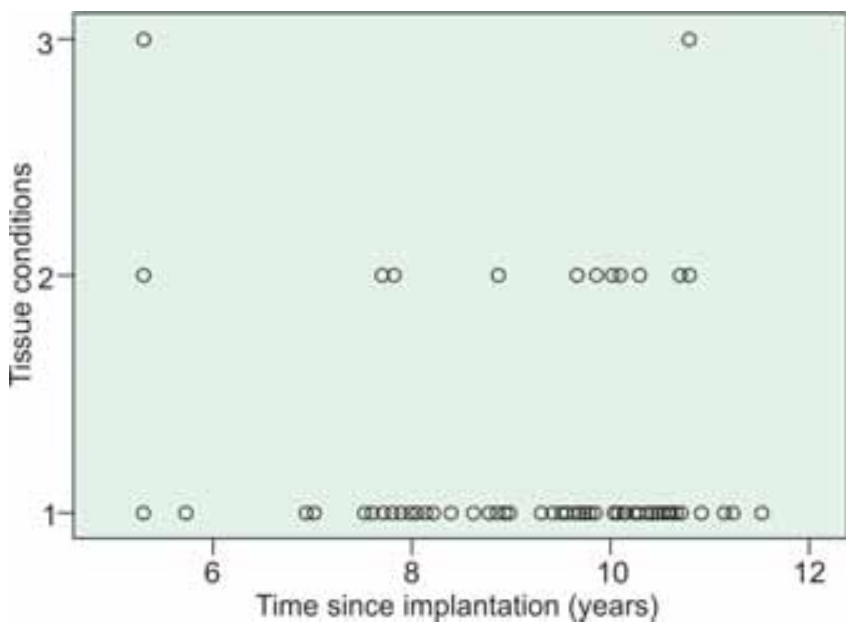

Fig. 4: Scatter plot showing healthy tissue conditions (1), peri-implant mucositis (2) and peri-implantitis (3) in dependence to the time of followup. It can be seen that peri-implant mucositis as well as peri-implantitis occur independent of time since implantation

their own criteria of success. ${ }^{5,22,23}$ In the present study, the prevalence of peri-implant disease associated with the TiOblast $^{\mathrm{TM}}$ dental implant system was assessed by evaluating SBI, PPD and changes in radiographic bone height, in accordance with generally accepted success criteria. ${ }^{9}$ These criteria have been shown to be important indicators of peri-implant disease which may lead to preterm loss of an implant.

The mean SBI, an indicator of the periodontal condition around an implant, showed no or only slight inflammation in $89 \%$ of the implants. This finding argues for a high level of oral hygiene and is in agreement with findings of previous studies. ${ }^{24,25}$ PPD reflects the amount of tissue resistance to probing. Peri-implant sites with increased PPD are associated with pathogenic microflora ${ }^{26}$ and may indicate peri-implantitis requiring treatment. The validity of probing the peri-implant mucosa has been evaluated in animal experiments. Lang et $\mathrm{a}^{27}$ determined the histological level of probe penetration in healthy and inflamed tissues around implants in beagle dogs. The authors concluded that probing around implants is a good technique for assessing the status of peri-implant mucosal health and disease. In the present study, the mean PPD was within the clinically acceptable range $(<5 \mathrm{~mm})$ and was similar to the results reported in the literature. ${ }^{25}$ The use of intra- and extraoral radiographs to determine changes in marginal peri-implant bone loss is widely accepted..$^{28,29}$ The pathological bone loss determined according to Albrektsson ( $\leq 2 \mathrm{~mm}$ in the first year and $0.2 \mathrm{~mm}$ in each subsequent year) ${ }^{20}$ was low in the present study, and most of the implants that exhibited pathological bone loss also showed increase in SBI and PPD. Thus, pathological bone loss may be attributable to inflammation in peri-implant tissues. ${ }^{1}$

The implant success rate was evaluated based on the above parameters. Peri-implant conditions were classified as healthy tissue, mucositis or peri-implantitis. This categorization clearly represents peri-implant tissue conditions and may be of use in planning further treatment. In the present study, the prevalence rates of peri-implant mucositis and peri-implantitis were lower than rates in other studies. ${ }^{1,30}$ At the patient level, smoking was significantly associated with peri-implant mucositis or peri-implantitis in the present study. This finding is in accordance to results in previously reported studies. ${ }^{31,32}$ The observation that pathological bone loss is also closely associated with excessive alcohol consumption was reported by GalindoMoreno et $\mathrm{al}^{33}$ as well. Irradiation has been shown to be a risk factor for peri-implant mucositis and peri-implantitis, as reported by Ben Slama et al. ${ }^{34}$

\section{CONCLUSION}

Within the limitations of this study, the following conclusions were drawn:

1. After a mean period of 9.12 years, the TiOblast dental implant shows a marginal rate of peri-implant disease.

2. Risk factors for peri-implant mucositis and periimplantitis were alcohol and nicotine abuse as well as prior irradiation.

\section{REFERENCES}

1. Berglundh T, Persson L, Klinge B. A systematic review of the incidence of biological and technical complications in implant dentistry reported in prospective longitudinal studies of at least 5 years. J Clin Periodontol 2002;29 Suppl 3:197-212; discussion 232-193.

2. Contreras A, Umeda M, Chen C, et al. Relationship between herpes viruses and adult periodontitis and periodontopathic bacteria. J Periodontol 1999;70(5):478-84.

3. Slots J. Human viruses in periodontitis. Periodontol 2000;53: 89-110.

4. Tonetti MS. Risk factors for osseodisintegration. Periodontol 2000, 1998;17:55-62.

5. Karoussis IK, Muller S, Salvi GE, et al. Association between periodontal and peri-implant conditions: A 10-year prospective study. Clin Oral Implants Res 2004;15(1):1-7.

6. Romeo E, Ghisolfi M, Carmagnola D. Peri-implant diseases: A systematic review of the literature. Minerva Stomatol 2004;53(5):215-30.

7. Offenbacher S. Periodontal diseases: Pathogenesis. Ann Periodontol 1996;1(1):821-78.

8. Savage A, Eaton KA, Moles DR, Needleman I. A systematic review of definitions of periodontitis and methods that have been used to identify this disease. J Clin Periodontol 2009;36(6): 458-67.

9. Albrektsson T, Isidor F. Consensus report. Implant Therapy. In: Lang NP, Karring T (Eds). Proceedings of the 1st European Workshop on Periodontology. Quintessence 1994:365-69.

10. Esposito M, Hirsch JM, Lekholm U, Thomsen P. Biological factors contributing to failures of osseointegrated oral implants (II). Etiopathogenesis. Eur J Oral Sci 1998;106(3):721-64.

11. Lindhe J, Berglundh T, Ericsson I, Liljenberg B, Marinello C. Experimental breakdown of peri-implant and periodontal tissues. A study in the beagle dog. Clin Oral Implants Res 1992;3(1): 9-16. 
12. Pontoriero R, Tonelli MP, Carnevale G, et al. Experimentally induced peri-implant mucositis. A clinical study in humans. Clin Oral Implants Res 1994;5(4):254-59.

13. Rasmusson L, Roos J, Bystedt H. A 10-year follow-up study of titanium dioxide-blasted implants. Clin Implant Dent Relat Res 2005;7(1):36-42.

14. Al-Nawas B, Gotz H. Three-dimensional topographic and metrologic evaluation of dental implants by confocal laser scanning microscopy. Clin Implant Dent Relat Res 2003; 5(3):176-83.

15. Wennerberg A, Albrektsson T. Suggested guidelines for the topographic evaluation of implant surfaces. Int J Oral Maxillofac Implants 2000;15(3):331-44.

16. Al-Nawas B, Kammerer PW, Morbach T, et al. Ten-year retrospective Follow-up Study of the TiOblast dental implant. Clin Implant Dent Relat Res 2010.

17. Muhlemann HR, Son S. Gingival sulcus bleeding-a leading symptom in initial gingivitis. Helv Odontol Acta 1971; 15(2):107-13.

18. Zechner W, Watzak G, Gahleitner A, et al. Rotational panoramic versus intraoral rectangular radiographs for evaluation of periimplant bone loss in the anterior atrophic mandible. Int J Oral Maxillofac Implants 2003;18(6):873-78.

19. Kullman L, Al-Asfour A, Zetterqvist L, Andersson L. Comparison of radiographic bone height assessments in panoramic and intraoral radiographs of implant patients. Int J Oral Maxillofac Implants 2007;22:96-100.

20. Albrektsson T, Zarb G, Worthington P, Eriksson AR. The longterm efficacy of currently used dental implants: A review and proposed criteria of success. Int J Oral Maxillofac Implants 1986;1(1):11-25.

21. Karoussis IK, Bragger U, Salvi GE, Burgin W, Lang NP. Effect of implant design on survival and success rates of titanium oral implants: A 10-year prospective cohort study of the ITI dental implant system. Clin Oral Implants Res 2004;15(1):8-17.

22. Buser D, Weber HP, Lang NP. Tissue integration of nonsubmerged implants. 1-year results of a prospective study with 100 ITI hollow-cylinder and hollow-screw implants. Clin Oral Implants Res 1990;1(1):33-40.

23. Ferrigno N, Laureti M, Fanali S, Grippaudo G. A long-term follow-up study of non-submerged ITI implants in the treatment of totally edentulous jaws. Part I: Ten-year life table analysis of a prospective multicenter study with 1286 implants. Clin Oral Implants Res 2002;13(3):260-73.

24. Gallucci GO, Doughtie CB, Hwang JW, Fiorellini JP, Weber HP. Five-year results of fixed implant-supported rehabilitations with distal cantilevers for the edentulous mandible. Clin Oral Implants Res 2009;20(6):601-07.

25. Benic GI, Jung RE, Siegenthaler DW, Hammerle CH. Clinical and radiographic comparison of implants in regenerated or native bone: 5-year results. Clin Oral Implants Res 2009;20(5): 507-13.

26. George K, Zafiropoulos GG, Murat Y, Hubertus S, Nisengard RJ. Clinical and microbiological status of osseointegrated implants. J Periodontol 1994;65(8):766-70.

27. Lang NP, Wetzel AC, Stich H, Caffesse RG. Histologic probe penetration in healthy and inflamed peri-implant tissues. Clin Oral Implants Res 1994;5(4):191-201.

28. Bragger U. Radiographic parameters: Biological significance and clinical use. Periodontol 2000, 2005;39:73-90.

29. Watzak G, Zechner W, Busenlechner D, et al. Radiological and clinical follow-up of machined- and anodized-surface implants after mean functional loading for 33 months. Clin Oral Implants Res 2006;17(6):651-57.

30. Simonis P, Dufour T, Tenenbaum H. Long-term implant survival and success: A 10 to 16-year follow-up of non-submerged dental implants. Clin Oral Implants Res 2010;21(7):772-77.

31. Lindquist LW, Carlsson GE, Jemt T. Association between marginal bone loss around osseointegrated mandibular implants and smoking habits: A 10-year follow-up study. J Dent Res 1997;76(10):1667-74.

32. Lindquist LW, Carlsson GE, Jemt T. A prospective 15-year follow-up study of mandibular fixed prostheses supported by osseointegrated implants. Clinical results and marginal bone loss. Clin Oral Implants Res 1996;7(4):329-36.

33. Galindo-Moreno P, Fauri M, Avila-Ortiz G, et al. Influence of alcohol and tobacco habits on peri-implant marginal bone loss: A prospective study. Clin Oral Implants Res 2005;16(5): 579-86.

34. Ben Slama L, Hasni W, De Labrouhe C, Bado F, Bertrand JC. Osteoradionecrosis and dental implants. Rev Stomatol Chir Maxillofac 2008;109(6):387-391; discussion 391-82. 